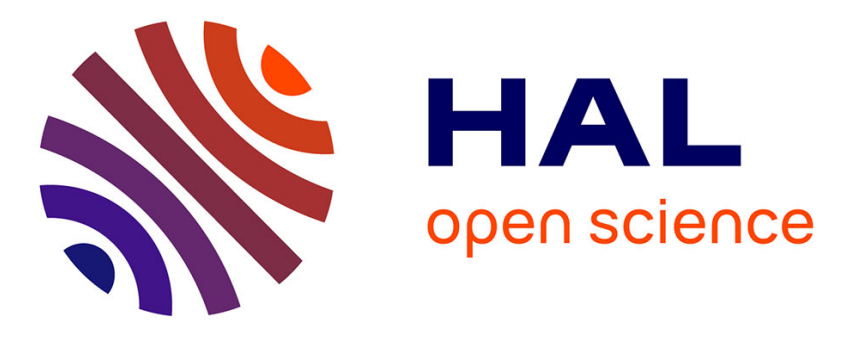

\title{
Modal analysis for optimal design of offshore wind turbine blades
}

\author{
Hicham Boudounit, Mostapha Tarfaoui, Dennoun Saifaoui
}

\section{To cite this version:}

Hicham Boudounit, Mostapha Tarfaoui, Dennoun Saifaoui. Modal analysis for optimal design of offshore wind turbine blades. 1st International Conference on Renewable Energy and Applications, ICREA 2019, Dec 2019, Casablanca, Morocco. pp.998-1004, 10.1016/j.matpr.2020.04.373 . hal02995520

\section{HAL Id: hal-02995520 \\ https://hal-ensta-bretagne.archives-ouvertes.fr/hal-02995520}

Submitted on 16 Jun 2021

HAL is a multi-disciplinary open access archive for the deposit and dissemination of scientific research documents, whether they are published or not. The documents may come from teaching and research institutions in France or abroad, or from public or private research centers.
L'archive ouverte pluridisciplinaire HAL, est destinée au dépôt et à la diffusion de documents scientifiques de niveau recherche, publiés ou non, émanant des établissements d'enseignement et de recherche français ou étrangers, des laboratoires publics ou privés.

\section{(c)(1)}

Distributed under a Creative Commons Attribution| 4.0 International License 


\title{
Modal analysis for optimal design of offshore wind turbine blades
}

\author{
Hicham Boudounit ${ }^{\mathrm{a}, \mathrm{b},{ }^{*}}$ Mostapha Tarfaoui ${ }^{\mathrm{b}}$, Dennoun Saifaoui ${ }^{\mathrm{a}}$ \\ a FSAC - UH2C, Laboratory of Renewable Energy and Dynamic Systems, Morocco \\ ${ }^{\mathrm{b}}$ ENSTA Bretagne, IRDL, UMR CNRS 6027, F-29200 Brest, France
}

\begin{abstract}
Throughout their operating life, offshore wind turbine blades are subjected to considerable wind forces. In order to ensure their durability and strength the intrados and extrados are bounded around spars, which are the skeleton that provide the necessary rigidity to the blade. Wind turbine blades are complex structures given the various scientific fields involved in their study, from aerodynamic to composite fatigue and failure analysis. Wind turbine blade is under coupled process of forces, so when we have the same natural frequency for the blade and exciting forces, the resonance is occurred. Which make the modal analysis of the blade of great importance, hence the scope of the present work, which deal with determining, the natural modes shapes and frequencies of three spars forms during free vibration, as well as for a $5 \mathrm{MW}$ horizontal axis floating wind turbine blade, to prevent and avoid resonance effect, using ABAQUS Finite element analysis software. The results show that the resonance effect does not occur for the blade and the proposed layup model provide enough resistance to the structure.
\end{abstract}

\section{Introduction}

We noticed over the last decade an exponential growth in the demand for electrical energy in the world, due to the increase of the population and the need of modern comfort. In order to respond to this ever-increasing demand and reduce the emissions of greenhouse gas [1-3], the wind energy sector has grown rapidly in the last few years.

Wind turbine blades are complex structures made of 3D surfaces resulting from the assembly of airfoil sections with various chord lengths, different twist angles, and pitch axis locations. They are usually constructed from several composites parts "generally glass-fiber/epoxy" and glued together, and they have special requirements, like being light and as rigid as possible [4,5] The increase in blade size engenders an increase in rotor and blade mass, which makes the requirements more severe for the main shaft, the tower and foundations that have to support the whole machine [6]. However, it reduces the number of individual turbine units and the cost of offshore farm.

\footnotetext{
* Corresponding author at: FSAC - UH2C, Laboratory of Renewable Energy and Dynamic Systems, Morocco.

E-mail address: hicham.boudounit-etu@etu.univh2c.ma (H. Boudounit).
}

The main objective of wind turbines blades design is to come out with a rotor that deliver the required output power for a range of speeds. Then, the rotor diameter and its geometry aerodynamic performance, strength and stiffness, have to be taking into consideration [7]. Moreover, the design of the rotor from an aerodynamic point of view, depend on various parameters such as power generator and control system [8]. According to [8,9], to optimize the structural design of the blade, it is necessary to combine objective, which are the power delivered with the constraints conditions as the mass-cost, strength, stiffness and stability. Moreover, act on spar cap layup parameters as a variable to achieve the objective and respect the constraints. Furthermore, authors of these papers [10-11] believe that by acting on spar caps one can reduce the blade mass and increase the edgewise stiffness. Therefore, it is of great importance defining the natural modes shapes and frequencies of the blade, especially for the first four-five modes, where the frequencies are lowest [12-13]. The experimental modal analysis (EMA) involve mechanical exciting to the structure using strikes with instrumented hammers depending on the system (Small -> lighter / Industrial $\rightarrow>$ heavier), and the vibration are measured using an accelerometer, or by acoustic / fluid systems [14-16].

In present paper, we aim to investigate the structural modal analysis of a $5 \mathrm{MW}$ horizontal axis floating wind turbine blade and the effect of spars shape by defining the natural frequencies 
Table 1

GFRP Mechanical Properties [1]

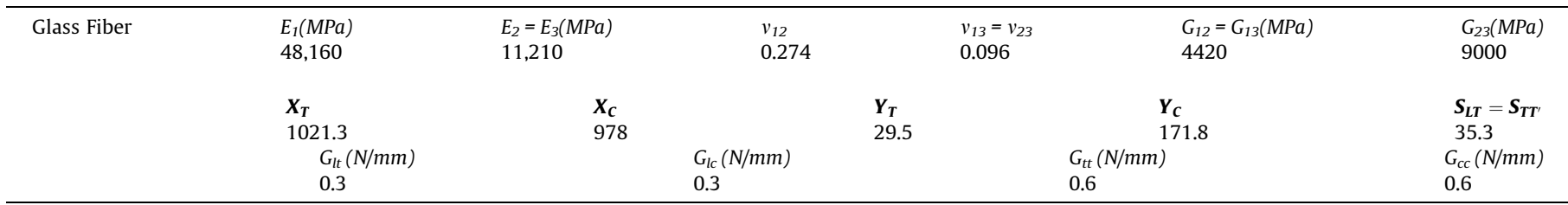

Table 2

Spars properties.

\begin{tabular}{lll}
\hline I shaped spar: "I" & $\begin{array}{l}\text { Material } \\
\text { Glass/epoxy }\end{array}$ & $\begin{array}{l}\text { Mass (t) } \\
1.48\end{array}$ \\
Box shaped spar: "B" & Glass/epoxy & 2.18 \\
8 shaped spar: "8" & Glass/epoxy & 2.58 \\
\hline
\end{tabular}

and characterize the vibration mode shapes of the three different spars and for the entire blade. Knowing those natural frequencies is the main key to avoid resonance effects and undesired structural elastic mechanisms on the blade.

\section{Description of the problem}

\subsection{Spars geometry}

The entire structure of a blade undergoes considerable effort over its operation duration. The rigidity of the blade is therefore essential to resist bending. Generally, two strips of reinforcement material are often used to allow local reinforcement. However, to ensure the shear strength, these two strips must be structurally

Table 3

Displacement and Frequencies for the first five modes.

\begin{tabular}{|c|c|c|c|c|c|c|}
\hline Model & & 1st Mode & 2nd Mode & 3rd Mode & 4th Mode & 5th Mode \\
\hline & $\mathrm{F}(\mathrm{Hz})$ & 0.3131 & 0.47093 & 0.63084 & 1.2755 & 1.8355 \\
\hline & $\mathrm{U}(\mathrm{mm})$ & 1.016 & 1.173 & 1.077 & 1.012 & 1.132 \\
\hline & $\mathrm{F}(\mathrm{Hz})$ & 0.34782 & 0.54810 & 0.97132 & 1.8505 & 2.3398 \\
\hline & $\mathrm{U}(\mathrm{mm})$ & 1.012 & 1.038 & 1.028 & 1.078 & 1.100 \\
\hline & $\mathrm{F}(\mathrm{Hz})$ & 0.31881 & 0.47595 & 0.87 & 1.6277 & 2.1270 \\
\hline & $\mathrm{U}(\mathrm{mm})$ & 1.013 & 1.036 & 1.028 & 1.064 & 1.085 \\
\hline
\end{tabular}

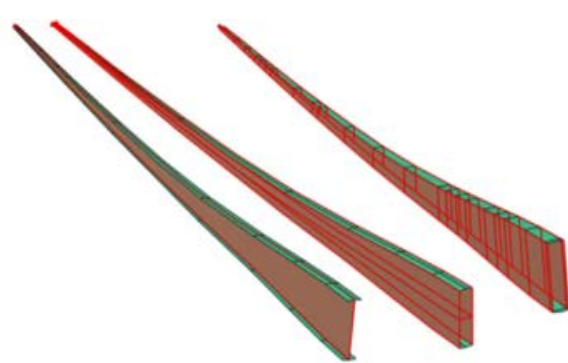

(a)

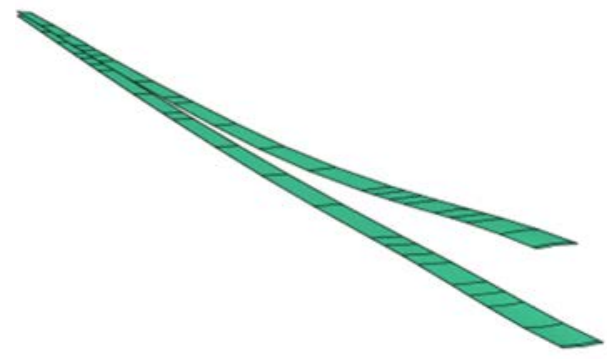

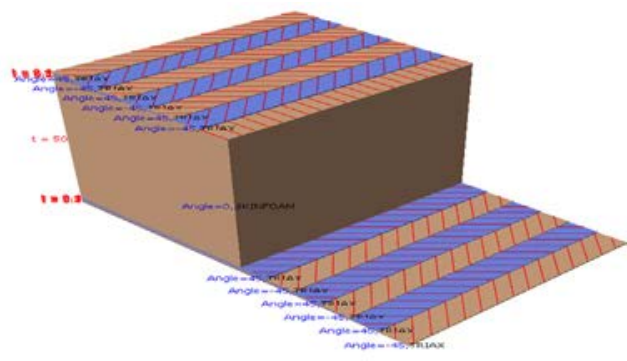

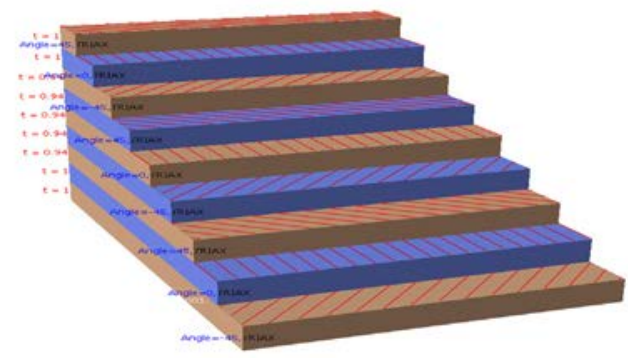

(b)

Fig. 1. Composite layup. 


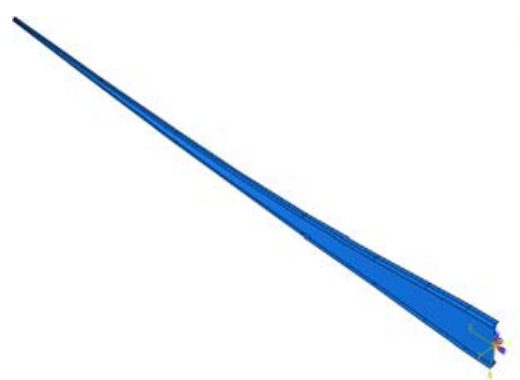

(a) Ishaped spar

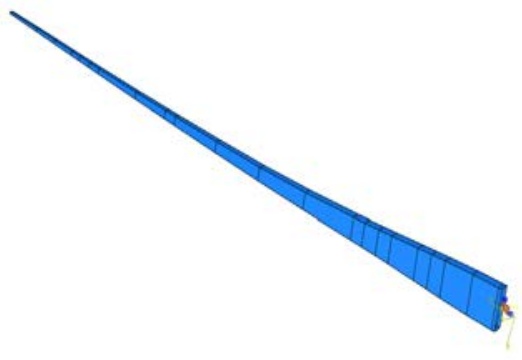

(b) Box shaped spar

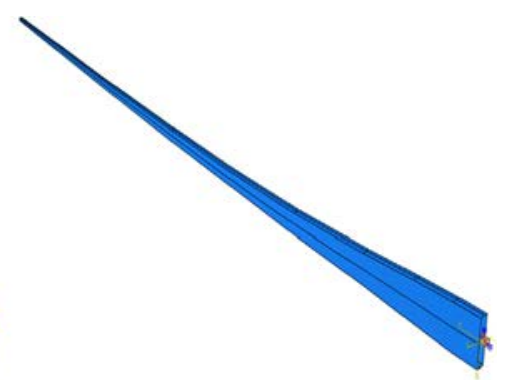

(c) 8 shaped spar

Fig. 2. Boundary condition on spars.
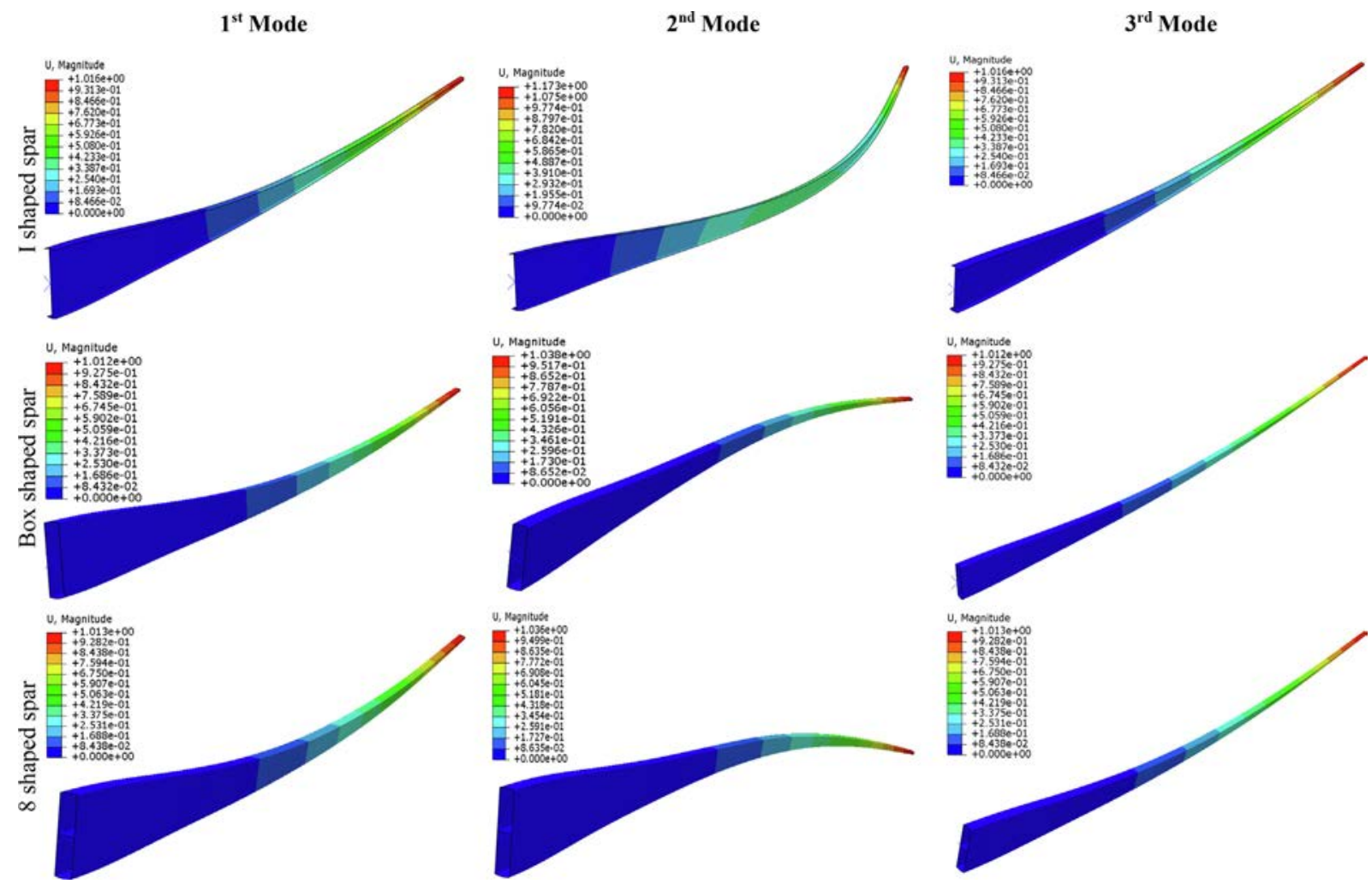

Fig. 3. Displacement of spars.

joined by a construction called spars. There are several ways to design those spars (either in the form of a beam connected by one or two longitudinal members or in the form of support structures of the load) [9]. The structural rigidity of the spar is essential because it prevents the blade from hitting the tower during rotation [15] but they also had to be lightweight.

The present paper is divided into two part, in the first intend to study the effect of spars geometries on natural mode shapes and determining their frequencies values, the second part is dedicated to define the natural mode of a $48 \mathrm{~m}$ wind turbine blade with spar.

In this study, we will focus on determining the mechanical behavior and performance of the three types of spars regrouped in Tables 2,3.

Table 2, regroup the weight corresponding to each spars type, according to the layup parameters "material- thickness". The I shaped spar is the lightest weight, followed by the box and 8 shaped spar.
Fig. 1, shows the layup parameters used for different zone of spars. Fig. 1a, represent the stratification model for the shear webs, which consists of a sandwich material, with six plies oriented [$45 / 45]_{3}$ and a total thickness of $2 \mathrm{~mm}$ of the skin and $50 \mathrm{~mm}$ of Foam.

Fig. $1 \mathrm{~b}$, represent the layup parameters of spars cap, giving by nine plies of glass fiber oriented $[-45 / 0 / 45]_{3}$ with a total thickness of $8.7 \mathrm{~mm}$.

\subsection{Boundary conditions}

To compare the performance of spars geometries, we have applied the same boundary conditions of Encastre type at the same location to all of the three geometries, Fig. 2.

The study consists on defining the natural modes and frequencies during free vibrations. 

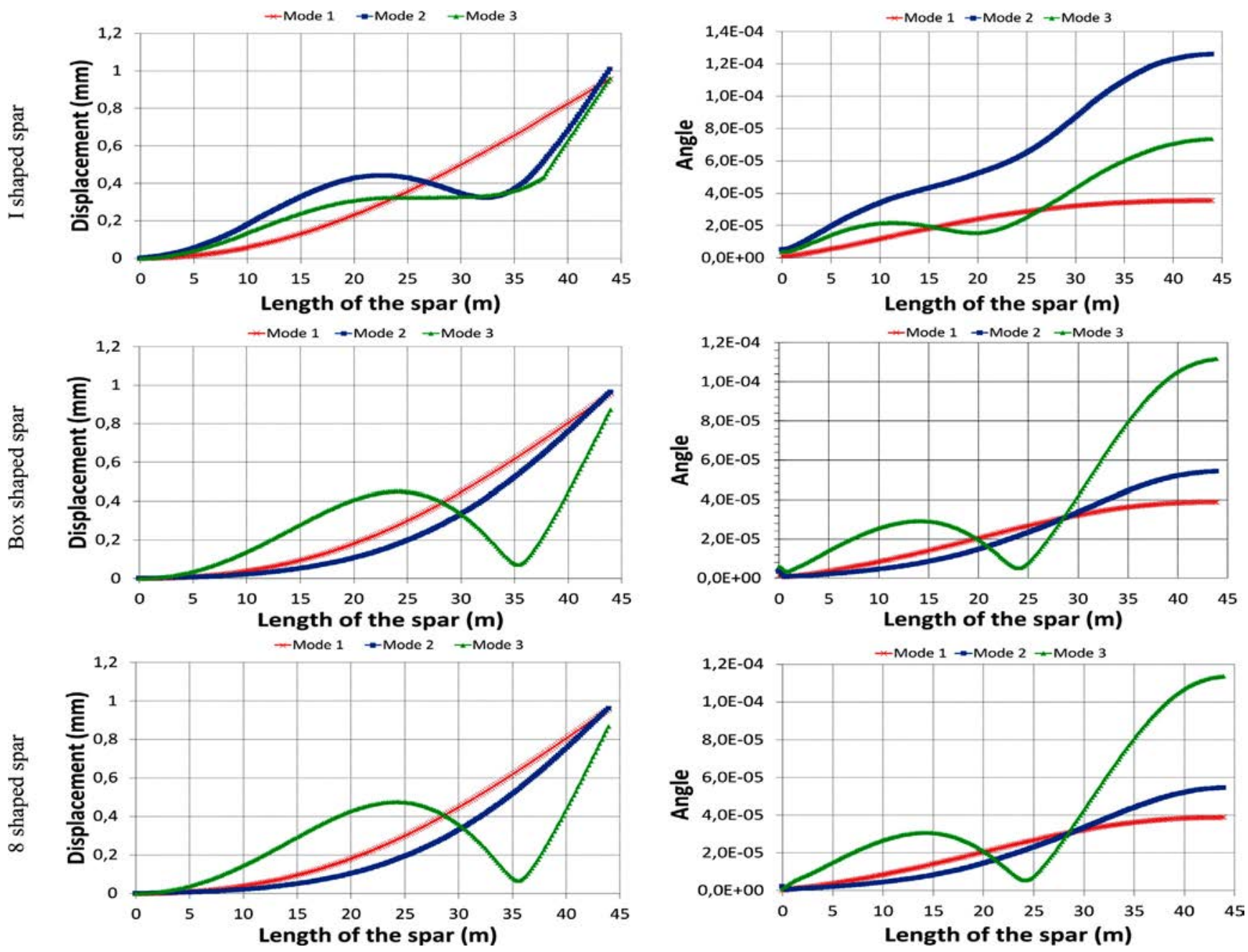

Fig. 4. Spars displacement and rotation angles.

Table 4

Computation results of the resonance effect for the three spars.

\begin{tabular}{|c|c|c|c|c|c|c|}
\hline & Models & 1st Mode & 2nd Mode & 3rd Mode & 4th Mode & 5th Mode \\
\hline \multirow[t]{3}{*}{$F_{\text {rot }} / F_{0, n}$} & I & 0.830 & 0.552 & 0.412 & 0.204 & 0.142 \\
\hline & Box & 0.748 & 0.474 & 0.268 & 0.141 & 0.111 \\
\hline & 8 & 0.816 & 0.546 & 0.299 & 0.160 & 0.122 \\
\hline
\end{tabular}
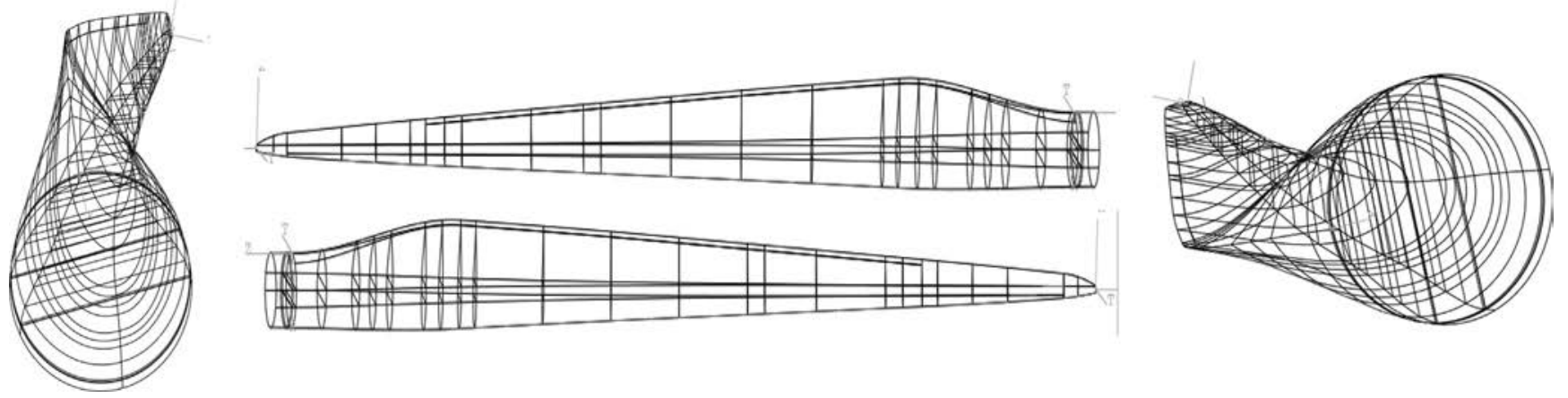

Fig. 5. $48 \mathrm{~m}$ wind turbine blade with box shaped spars. 


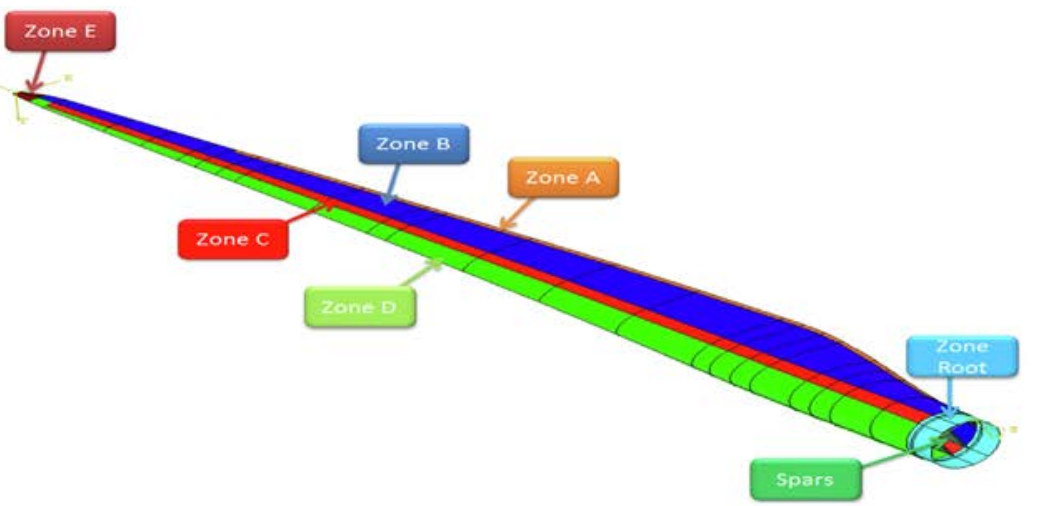

\begin{tabular}{lc} 
Zone (A) & Laminate \\
\hline Zone (B) & Sandwich \\
\hline Zone (C) & Laminate \\
\hline Zone (D) & Sandwich \\
\hline Zone (E) & Laminate \\
\hline Zone (Root) & Tick Laminate
\end{tabular}

(a)

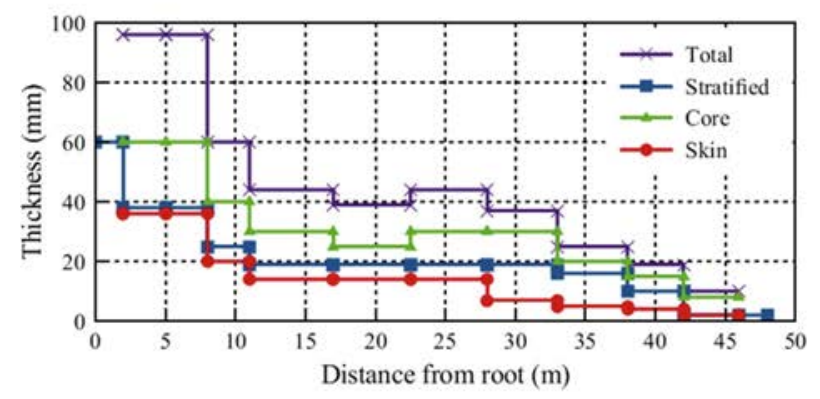

(b)

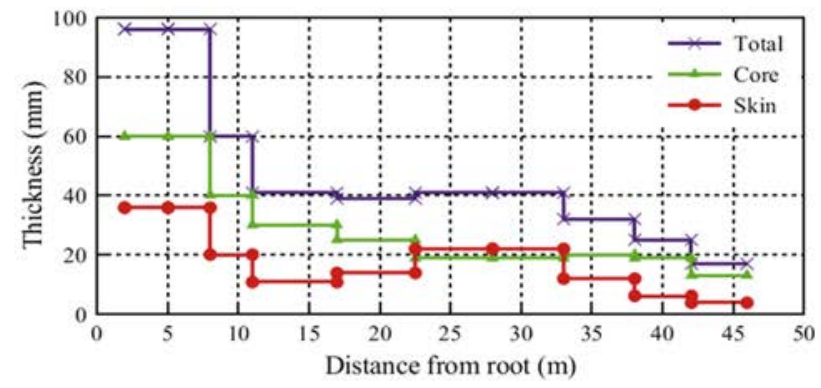

(c)

Fig. 6. Blade composite lay-up parameters.

\section{Results and discussion}

\subsection{Spars modal analysis}

Fig. 3 shows the displacements of the three spars with a scale (x4600) in order to be seen in the visualizations. Moreover, Fig. 4 shows the variation of the displacement and rotation angle with spars length for the three first modes.

The most prominent modes where the structure vibrates more are those with the lowest frequencies (mode 1 and 2). According to Germanischer Lloyd Wind Energy GmbH regulations for certification and standards for wind turbines, to avoid the phenomenon of resonance, we have to check the condition giving by equation (1):

$F_{\text {rotation }} / F_{0, n} \leqslant 0.95$

with

$F_{\text {rotation }}=0.267$

Applying this condition for the first five modes, we concluded that the effect of resonance does not occur for the three models, Table 4.

After comparing the three spars from different points of view: rigidity as well as the ratio mass/cost and considering the results of this study, we conclude that box shaped spars are the most adequate for our case, so for blade vibration modes study, one used box shaped spars as shown in Fig. 5 .

\subsection{Blade modal analysis}

Fig. 6a, shows the stratification model followed for the blade with box shaped spars. Fig. 6b, illustrates the distribution of materials for the blade surface shell (intrados and extrados). In addition,
Fig. 6c, shows the material thickness for the spar with its length and table 5 list the orientation of the composite materials.

Table 6 , regroups the main properties of the blade according layup parameters giving in Fig. 6, and materials properties giving in Table 1.

The modes shapes results for the blade are list in Fig. 7, and the variation in blade rotation angle and displacement with length are given in Fig. 8.

We concluded that the ad of intrados and extrados to the spars reduce the natural frequencies of the whole structure and consequently reduce the ratio of frequencies in the condition for certification given by Germanischer Lloyd Wind Energy GmbH. Then the effect of resonance does not occur for the blade (Table 7).

Table 5

Composite materials orientation.

\begin{tabular}{ll}
\hline UD & 0 \\
Biax & {$[-45 / 45]$} \\
Triax & {$[-45 / 0 / 45]$} \\
\hline
\end{tabular}

Table 6

Blade properties.

\begin{tabular}{ll}
\hline Length & $48 \mathrm{~m}$ \\
Mass & 12.18 tons \\
Airfoil & NACA 4424 \\
\hline
\end{tabular}

Table 7

Computation results of the resonance effect for the blade.

\begin{tabular}{llllll}
\hline & 1st Mode & 2nd Mode & 3rd Mode & 4th Mode & 5th Mode \\
\hline $\mathrm{F}(\mathrm{Hz})$ & 0.811 & 1.100 & 1.908 & 3.546 & 3.844 \\
$\mathrm{U}(\mathrm{mm})$ & 1.010 & 1.026 & 1.005 & 1.363 & 1.110 \\
$F_{\text {rot }} / F_{0, n}$ & 0.321 & 0.236 & 0.136 & 0.073 & 0.068
\end{tabular}




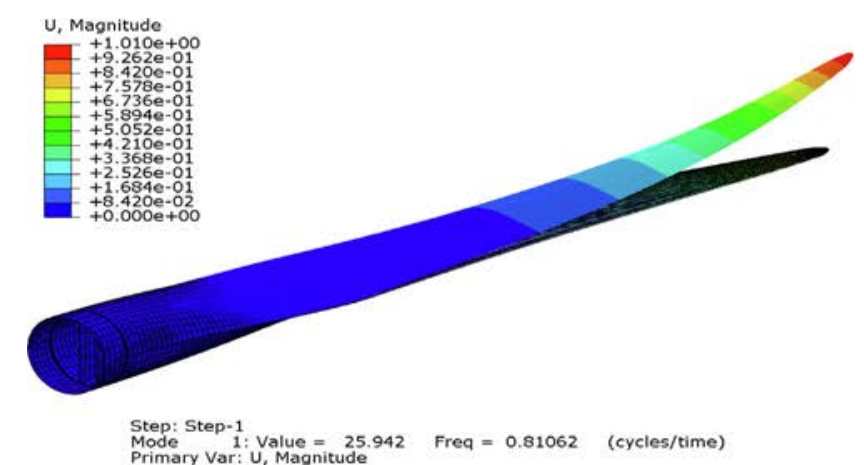

(1) $1^{\text {st }}$ Mode

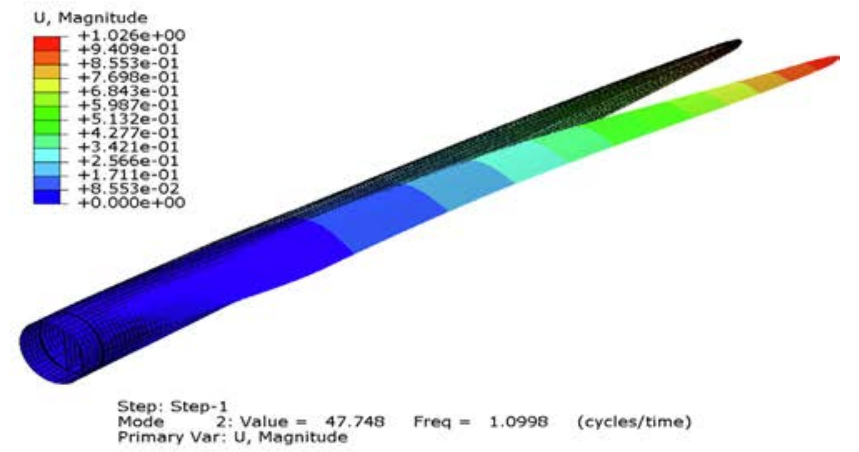

(2) $2^{\text {nd }}$ Mode
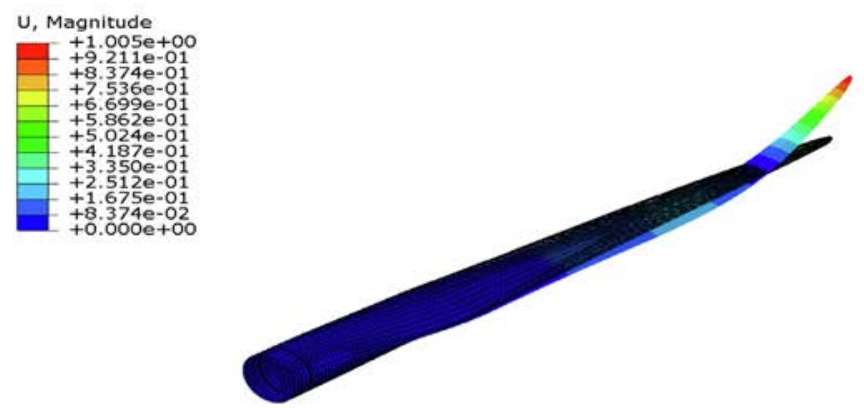

Step: Step- -1
Mode $3:$ Value $=143.69 \quad$ Freq $=1.9078 \quad$ (cycles/time)
Primary Var: U, Magnitude

(3) $3^{\text {rd }}$ Mode

Fig. 7. Blade natural modes shapes.
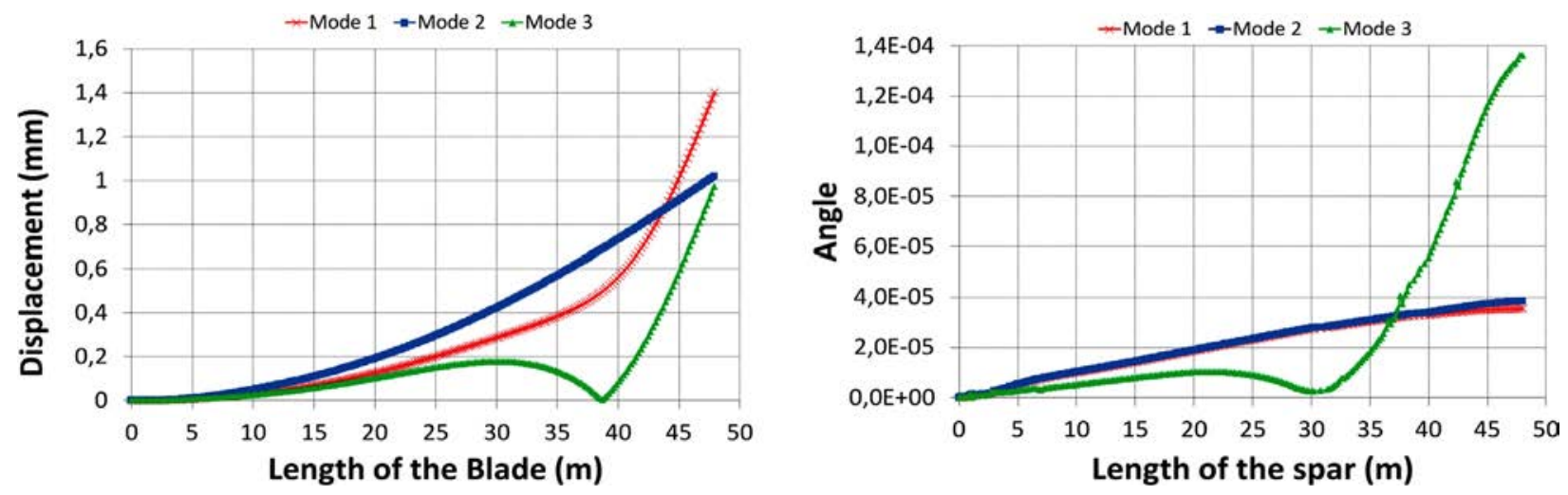

Fig. 8. Displacement and rotation of the blade.

\section{Conclusion}

The performed modal analysis gives estimations of lower five natural frequencies and mode shapes, for the investigated spars shapes and for a $48 \mathrm{~m}$ wind turbine blade with box shaped spars. We performed a modal analysis on all different structures and the results of natural frequencies and mode shapes have been checked to avoid the resonance mode of the system. The present investigation shows that numerical simulation can be considered as a powerful tool to reproduce the experimental approach, and it offers the possibility of predicting, natural frequencies and mode shapes using the modal analysis technique. It also show that the resonance effect does not occur for the blade and the proposed layup model provide enough resistance to the structure.

\section{CRediT authorship contribution statement}

Hicham Boudounit: Conceptualization, Data curation, Formal analysis, Software, Validation, Visualization, Writing - original draft, Methodology. Mostapha Tarfaoui: Methodology, Supervision, Validation, Visualization. Dennoun Saifaoui: Methodology, Supervision, Validation, Visualization.

\section{Declaration of Competing Interest}

The authors declare that they have no known competing financial interests or personal relationships that could have appeared to influence the work reported in this paper. 


\section{References}

[1] H. Boudounit, M. Tarfaoui D, Saifaoui M, Nachtane, Structural Analysis of Offshore Wind Turbine Blades Using Finite Element Analysis. Wind Engineering (2019)

[2] T. Mostapha, M. Nachtane, H. Boudounit, Finite element analysis of composite offshore wind turbine blades under operating conditions, J. Therm. Sci. Eng. Appl. 12 (1) (2020).

[3] M. Tarfaoui., M. Nachtane, O. R. Shah, H. Boudounit, Numerical Study of the Structural Static and Fatigue Strength of Wind Turbine Blades, Materials Today Proceedings May (2019).

[4] M. Nachtane, M. Tarfaoui, D. Saifaoui, A. El Moumen, H. Boudounit (2017, August). Caractérisation mécanique d'une hydrolienne en matériau composite dans un environnement marin.

[5] H. Boudounit, M. Tarfaoui, D. Saifaoui (2017). Modélisation et simulation du comportement mécanique d'une pale composite d'une éolienne flottante. In 3ème Congrès national en sciences physiques, technique et applicationsSPTA.

[6] H. Boudounit, M. Tarfaoui, D. Saifaoui (2017, March). Modeling and simulation of the mechanical behavior of a composite blade of a floating wind turbine.

[7] H. BOUDOUNIT, D. SAIFAOUI, Wind Farm Design Approach: Feasibility and Optimization Study-Case of the Dakhla Site in Morocco. Journal of Applied Science and Environmental Studies, vol. 3, no 1, p. 3-1)(2020) 26-36.
[8] J. Zhu, X. Cai, P. Pan, R. Gu, Optimization design of spar cap layup for wind turbine blade, Front. Struct. Civil Eng. 6 (1) (2012) 53-56.

[9] P. Roth-Johnson, R.E. Wirz, E. Lin, Structural design of spars for 100-m biplane wind turbine blades, Renew. Energy 71 (2014) 133-155.

[10] T.T. Thomas, M.M. Narkhede, B.S. Patil, A. Mogra, Analysis Of Wind Turbine Blade Having I Shaped Spar Using Both Epoxy Fiber And Carbon Fiber Using FEM, Mater. Today:. Proc. 4 (2) (2017) 2573-2579.

[11] M. Rosemeier, and M. Bätge. "A concept study of a carbon spar cap design for a $80 \mathrm{~m}$ wind turbine blade.” J. Phys. Conf. Ser. Vol. 524. No. 1. IOP Publishing, (2014).M. Rosemeier, and M. Bätge. "A concept study of a carbon spar cap design for a $80 \mathrm{~m}$ wind turbine blade." Journal of Physics: Conference Series. Vol. 524. No. 1. IOP Publishing, (2014).

[12] X. Cai, P. Pan, J. Zhu, R. Gu, The analysis of the aerodynamic character and structural response of large-scale wind turbine blades, Energies 6 (7) (2013) 3134-3148.

[13] G.C. Larsen, M.H. Hansen, A. Baumgart, I. Carlén, Modal analysis of wind turbine blades, Risø National Laboratory, Roskilde, Denmark, 2002, pp. 1-72.

[14] W.C. De Goeij, M.J.L. Van Tooren, A. Beukers, Implementation of bendingtorsion coupling in the design of a wind-turbine rotor-blade, Appl. Energy 63 (3) (1999) 191-207.

[15] K.Y. Maalawi, H.M. Negm, Optimal frequency design of wind turbine blades, J. Wind Eng. Ind. Aerodyn. 90 (8) (2002) 961-986.

[16] Cunha, A., \& Caetano, E. (2006). Experimental modal analysis of civil engineering structures. 